\title{
The Effect of Different Price Promotion Ways on Consumers' Purchasing Intention
}

\author{
Yong Zhang, Jiayue Deng, Yuxin Xu \\ School of Management, Jinan University, Guangzhou, China \\ Email: 893124597@qq.com
}

How to cite this paper: Zhang, Y., Deng, J.Y. and Xu, Y.X. (2017) The Effect of Different Price Promotion Ways on Consumers' Purchasing Intention. American Journal of Industrial and Business Management, 7, 1192-1208.

https://doi.org/10.4236/ajibm.2017.710085

Received: September 18, 2017

Accepted: October 23, 2017

Published: October 26, 2017

Copyright $\odot 2017$ by authors and Scientific Research Publishing Inc. This work is licensed under the Creative Commons Attribution International License (CC BY 4.0).

http://creativecommons.org/licenses/by/4.0/

\begin{abstract}
Price promotion, as one of the most popular promotions on the Internet, has a certain influence on consumers' purchasing intention. It is great significance to explore the relationship and related factors between price promotion and consumers' purchasing intention. The study explores the impact of two common kinds of online price promotion on consumers' purchasing intention, and examines the moderating effects of product complementarity in the above relationship. The study finds that the interaction between complementary products and price promotion has a significant impact on consumers' purchasing intention, mental account plays a mediating role in the process. Specifically, in the case of complementary products, perceived promotional risk has greater influence on consumers' purchasing intention, and consumers tend to choose "price deduction over a given purchase amount". Under the condition that the product does not exist complementary, perceived promotional benefit has greater effect on consumers' purchasing intention, and consumers tend to choose "unveiling promotion price" promotion. The conclusion of this study enriches the theoretical research of the related online promotion, and also can help the network merchants to formulate effective promotion strategies.
\end{abstract}

\section{Keywords}

Price Promotion, Perceived Promotional Benefit, Perceived Promotional Risk, Purchase Intention

\section{Research Background}

With the popularity of Internet and network equipment applications, online shopping has become a daily way of consumer shopping. Due to the improving of the online shopping convenience and speed, various online shopping protection 
methods continue to be implemented, the amount of online transactions are also rising year by year. According to CNNIC (China Internet Network Information Center) 39th China Internet Development Statistics report shows that as of December 2016, the size of online shopping users reached 448 million [1]. It can be seen, online shopping has become an important part of people's life.

At present, online retail platform Taobao, Jingdong, Tmall and other online shops are numerous, the homogenization phenomenon of network shop products is more and more serious, and many online store operators found that promotion is an effective incentive behavior. Among them, price promotion is one of the most popular promotions because of its effectiveness and ease of implementation. In the face of endless promotions and information asymmetry in online shopping, consumers have different willingness to accept various promotional activities.

At present, online promotion is a common phenomenon, and many scholars have studied it. The research is mainly divided into two aspects, one is the comparison of different promotional methods, such as Han \& Tian, who compared the cash discount, return tickets, gifts of the three preferential ways and found that consumers' preference for cash discounts is bigger, minimal gifts preferences [2]. The second research is the promotion intensity, Deng (2005) combined the cost profit and concluded that the price cut $12.15 \%$ is the optimal choice through the mathematical model comprehensive analysis [3]. But now the common promotion ways have price deduction over a given purchase amount, discounts or unveiling promotion price, and consumers are usually need to purchase a certain number or amount to meet the promotion conditions, such as the second half price, full 399 minus 100 and so on. Overall, most scholars study the range of price and various types of promotion. Less research is the same type of promotions and the latest network marketing phenomenon, and there is also a lack of research on how sales products influence promotional effects. Moreover, online malls or stores have not yet formed a unified promotion rule or theory. Obviously, there is still room for literature research on online promotion.

Therefore, based on the same type of promotion, this paper compares the impact of two price promotion ("price deduction over a given purchase amount" and "Unveil promotion price") on consumers' purchasing intention and its mechanism. Moreover, product complementarity is used as a moderator variable, this paper discusses consumers prefer which way of promotion under different products complementarity situation, and then provides effective promotion advice for the network merchants.

\section{Literature Review}

\subsection{Price Promotion}

In theory, promotion can basically be divided into "sales promotion" and "price promotion" two major categories. "Sales promotion" refers to the practice of 
selling goods and other items by coupons, gifts and samples, etc. "Price promotion" refers to the fact that the actual selling price is lower than the price, so that the customer can get a discount on the price. Raghubir et al. (2004) argues that price promotion refer to giving a lower price for a product or service or giving more products or services at the same price when making a sales activity [4]. Based on the above definition, the price promotion in this study refers to reducing the original price of network products or services in order to achieve the purpose of stimulating sales.

Online price promotion include freight discount, return red envelopes, cash voucher, price deduction over a given purchase amount, discount promotions and so on. By tracking the price promotion of online stores on Taobao, Tmall, Jingdong and other online retail platforms, we found that "price deduction over a given purchase amount" and "Unveil promotion price" are two of the most common price promotion. "price deduction over a given purchase amount" generally appear in the page more eye-catching position to attract the attention of consumers, which means consumers can get the price discount and reduce the actual payment amount when they buy a certain amount of money, for example full 199 minus 100. "Unveil promotion price" refers to the goods display two kind of prices on the webpage, one is the original price, one is the promotion price, such as promotional price 80 , the original price of 100 . In this way, consumers are directly aware of changes in commodity prices and are directly informed of savings.

In recent years, some domestic scholars have done some research on price promotion, but there is little comparative research on two kinds of price promotion: "price deduction over a given purchase amount" and "Unveil promotion price". Therefore, based on two most common price promotion, it is important to explore their impact on consumers' purchasing intention in online.

\subsection{Product Complementarity}

Complementary products refers to two different products can complement each other to meet the same need. products are complementary shows two products need to cooperate with each other to meet the same needs of consumers; products are not complementary means two products may be substitutes or the relationship between the two is very small, so that cannot meet the same needs. Sarin et al. (2003) pointed that if new products are sold with complementary products, consumers will perceive the signal that new products are compatible with complementary products and complementary products are available. This can reduce the risk of consumer online shopping and accelerate the market penetration rate of new products [5]. The product complementarity defined in this paper is based on whether the two products are complementary. If the two products need to be used together, they are complementary; conversely, if two products can replace or have little relationship, there is no complementarity between the two products.

Previous studies have found that complementary marketing methods can affect 
consumers' online purchasing behaviors. However, the research on which complementary marketing ways combined with which kind of online promotions can increase their influence has not yet appeared, which calls for enriching the research of the moderating effects of complementary products.

\subsection{Promotion Benefit and Risk}

According to the theory of psychological accounts, consumers decided whether or not to perform a certain behavior by comparing the potential benefit or potential risk that some behavior may cause. Therefore, when faced with different promotions, consumers should take into consideration their perceived benefit and risk.

\subsubsection{Perceived Promotional Benefit}

Early foreign related theories believe that cost-saving is the only promotional benefit that consumers want to obtain, and consumers wound choose to buy goods with great promotional power. With the increase in promotion methods and the diversification of consumer psychology, cost-saving is no longer the only promotional benefit that consumers want to get. Hirschman \& Holbrook (1994) pointed out that the promotion to consumers was a series of interests. They summed up the six kinds of representative interests, including monetary savings, improved product quality, shopping convenience, the opportunities for selfexpression, exploration and entertainment [6]. Later, scholars made different classifications of promotional benefit. Laurent et al. (2011) divided promotional interests into utilitarian interests and hedonic interests. Specifically, the utilitarian interests include cost-saving, commodity quality and convenience, and the hedonic interest consists of self-worth, exploration and entertainment interests [7]. Kopalle et al. (1996) attributed the impact of promotions on consumer purchasing decisions in two ways, including that promotional activities reduced the actual costs that consumers spent on buying goods and that promotion enable consumers to obtain additional benefit [8]. Raghubir et al. (2004) divided the promotional impact on consumers into three areas: economic impact, information impact, and emotional impact [4].

Therefore, promotions not only bring economic savings to consumers, but also include psychological benefit and so on. Based on the promotion theory and the characteristics of online shopping, the perceived promotional benefit of this study refers to the cost-saving, goods quality and convenience brought by the promotion activities for consumers. Cost-saving is promotion for consumers to save costs; Goods quality is that consumers spend less and enjoy higher quality; Convenience means that the promotion reduces the search cost and decisionmaking cost of consumers, saving time and energy.

\subsubsection{Perceived Promotional Risk}

Bauer (1960) first introduces the perceived risk from psychology, which refers to the risk that the purchased product may not achieve the desired effect when it is 
used, and perceived risk can be divided into economic risk, financial risk, physical risk and social risk [9]. In consumer behavior, the consumers' purchasing risk mainly includes utility risk, economic risk and reputation risk. Perceived risk theory holds that perceived risk is the intrinsic attribute of buying new goods. Based on the traditional definition of perceived risk, early foreign theories defined online perceived risk as the subjective expectation of online financial loss. $\mathrm{Hu}$ (2011) pointed out that the promotion risk of consumers buying goods in online mainly included the money, goods quality and the extent of perceived control [10]. Perceived control refers to the promotion strategy may cause consumers to doubt the motive, authenticity and other negative effects, and even those who think they are controlled by the marketers.

Based on the characteristics of the online promotion and the above definition, this study considers that the perceived promotional risk of consumers mainly depends on the amount of the cost, goods quality and the extent of perceived control.

\subsection{Purchase Intention}

Seymour (1950) found that $62 \%$ of respondents said they wanted to buy and actually bought [11]. Bagozzi et al. (1989) found that $6 / 7$ of the researchers' intentions and behaviors were closely related [12]. Shin (2011) pointed out that in electronic products, consumer purchasing intention increased by $1 \%$, the market share increased by $0.18 \%$ [13]. Parasuraman (1997) used the two dimensions of "positive" and "negative" to discuss purchase intention. The study suggested that if consumers had a negative purchase intention for the product, it would reduce the possibility of buying the product; on the contrary, if consumers had a positive purchase intention, it would increase the likelihood of buying the product [14]. Therefore, to some extent, to judge the more effective ways of price promotion of consumer buying behavior, we can explore its impact on consumers' purchasing intention.

In terms of intention, Fishbein \& Ajzen (1975) argued that intention was the subjective possibility of an individual performing a particular act, that one's will was influenced by one's attitude and it could lead to conscious behavior [15]. Domestic and foreign scholars have studied the purchase intention in many aspects. Dodds et al. (1991) explicitly defined the purchase intention as the possibility that the consumer intended to purchase a particular product [16]. Han \& Tian (2005) also proposed that purchase intention was the possibility of consumers to purchase specific products [2]. However, Zhu (1989) regarded the purchase intention as a psychological requirement of the consumer, which was the prelude to the consumer's purchase action [17]. Based on the study of purchase intention by scholars both at home and abroad, the purchase intention of this study refers to the possibility of consumers' purchasing goods under different promotions, and the level of purchase will affect consumers' purchasing decisions. 


\section{Hypothesis}

\subsection{Research Hypothesis of Promotion Ways}

The psychological account theory suggests that consumers are likely to perceive different promotional values from different ways of editing information. Studies have shown that the choice of goods when different strategies to express the benefit of the psychological effects of consumers is different. In addition, the framing effect in consumer psychology shows that consumer behavior is different when faced with different descriptions but with the same practical utility. Tversky \& Kanheman (1981) proved that the role of framing effect on decision-making behavior in the study, proved that the decision preference depends on the description of decision problem by the choice of currency selection problem and loss of life [18]. Therefore, we propose that consumers will have different purchasing intention and will prefer some kind of promotion program when faced with different promotional environments.

For complementary products, $\mathrm{Hu}$ (2012) research shows that whether both the two products are promoted or only one product is promoted have impact on the spread and profit of both product [19]. Xu et al. (2005) pointed out that in the purchase of new energy vehicles, the provision of complementary products is very important and can have a positive impact [20]. Therefore, we can believe that there is a certain relationship between product complementarities and promotion methods.

Duan (2007) suggested that offering discounts when bundling complementary goods could reduce consumers' perceived risk [21]. Krishna et al. (2002) found that the more prominent discount editing methods could lead to more transactions [22]. At the same time, the research results show that the more money purchased, the purchase risk is greater and the consumers' purchasing intention will be reduced. Tao (2011) pointed out that bundling products with low complementarity would reduce customer loyalty [23]. Therefore, in the case of complementary products, "price deduction over a given purchase amount" this kind of intuitive discount can bring more purchase intention; When the products are not complementary, if consumer need to buy more than two products to reach the "price deduction over a given purchase amount" conditions, they will spend unnecessary money. At this point, the "price deduction over a given purchase amount" promotion effect may be general, consumers will be more willing to accept the promotion of "Unveil promotion price".

Accordingly, this paper proposes the following hypotheses:

$\mathrm{H} 1$ : there is an interaction between different price promotion ways and product complementarity, which have a significant impact on consumers' purchasing intention.

H1a: In the case of complementarity of products, the "price deduction over a given purchase amount" approach can lead greater willingness to buy.

H1b: In the absence of complementarity of products, the "Unveil promotion price" approach can lead greater willingness to buy. 


\subsection{Research Hypothesis of Psychological Account and Purchase Intention}

Based on the mental accounting theory, in the face of different online price promotion, consumers' willingness to buy will be based on their own perceived promotional benefit (cost-saving, quality experience, shopping convenience) and perceived promotional risk (money, goods quality, the extent of perceived control). Sondergaard et al. (2005) pointed out that consumers had a general attitude at the time of shopping, then made specific benefit and risk assessments, and finally generated purchase intention [24]. Shi (2009) showed that there is a certain connection between consumer perceived risk and perceived benefit in the domestic online shopping environment [25]. Therefore, we can believe that perceived promotional benefit and perceived promotional risk have a certain influence on purchase intention.

The above mentioned, the complementary product bundling can reduce consumers' risk. Moreover, the study also find that when the two kinds of product bundling are highly complementary, it will affect the consumers' perception of quality, and consumers' perception of the quality of goods is belonging to promotion risk. Therefore, we believe that in the case of complementarity of products, consumers have a significant difference of perception risk for different promotion ways. However, there is no significant difference between consumers' perceived promotional risk in the case of no complementarity between products, and perceived promotional benefit are more significant influence on consumer purchase intention.

Accordingly, this paper proposes the following hypotheses:

H2: psychological accounts (perceived promotional benefit and perceived promotional risk) play a mediating role in the impact of price promotion and product complementarity on purchase intention.

H2a: In the case of complementarity of products, perceived promotional risk has a greater impact on consumers' purchasing intention.

$\mathrm{H} 2 \mathrm{~b}$ : In the absence of complementarity of products, perceived promotional benefit has a greater impact on consumers' purchasing intention.

\section{Research Methods}

This paper reviews the literature of online promotion and consumer purchase intention. Based on the theory of psychological accounts, this paper puts forward the research model of the influence of network price promotion on consumer purchase intention. In order to improve the quantitative research of this paper, this study uses SPSS and AMOS as the main statistical tools to analyze the survey data to verify whether the research model and assumptions are established.

The variables measured in this study are based on the foreign scale and combined with the specific contents of this experiment. The measurement of perceived promotional benefit refers to Chandon et al. (2000), which is measured by 
3 items including cost savings, quality experience and shopping convenience [26]. Perceived promotional risk measurement uses the Sweeney et al. (1999) method, which is measured by 3 items including money, goods quality, the extent of Perceived control [27]. For the measurement of purchase intention, we mainly refer to the scale compiled by Dodds et al. (1991), which has three items [16]. All subjects were measured by Likert's point scale ( 1 = "totally disagree"; 7 = "very agree").

In this experiment, 272 college students were invited to participate in the experiment. A total of 215 valid data were collected, with an effective rate of $79 \%$. Four experimental scenarios were designed based on price promotion ("price deduction over a given purchase amount" and "Unveil promotion price") and product complementary or not, and participants were randomly assigned to one of the situations.

In the experimental process, each experimental questionnaire in four experimental scenarios consists of three parts. The first part is the introduction and screening of respondents; the second part is the formal questionnaire. Participants firstly read the experimental materials, and then evaluate the perception promotional benefit, perceived promotional risk and purchase intention; The third part is the demographic characteristics of the participants, including gender, age, exposure to education and monthly income. To measure these items, all use likert 7 point scale score. The whole experiment was completed in about 30 minutes.

\section{Data Analysis}

1) Manipulation test

As mentioned above, the product complementarity defined in this paper is based on whether the two products are complementary. If the two products need to be used together, they are complementary; conversely, if two products can replace or have little relationship, there is no complementarity between the two products. In this paper, coffee and coffee partners show that there are complementary products, and coffee and milk tea indicate that there is no complementarity between products. The complementary manipulation of stimulants was tested. The results were consistent with the experimental control, and the degree of complementarity between coffee and coffee-mate was higher than that of coffee and milk tea $\left(M_{\text {coffee and coffee-mate }}=1.74, M_{\text {coffee and milk tea }}=1.14, P<0.05\right)$.

At the same time, in order to control the subjects' gender, age, monthly income, educational background and other factors, 160 valid data were randomly selected to guarantee the individual characteristic information of each test group as identical as possible. There were 40 people in each group, the ratio of male and female was $50 \%$ respectively, they are between the ages of 18 and 25, the education was undergraduate, and the monthly income was mainly under 3499 and below. The demographic variables of the four experimental scene groups were well controlled. 
2) Moderating effect analysis

According to the method of Wen et al. (2005) [28], the interaction effect is the moderating effect when the independent variable and the moderator variable are categorical variables. This study focuses on promotion way, Product complementarity, promotion way and Product complementarity as independent variables, purchase intention, perceived promotional benefit and perceived promotional risk as dependent variables. The variance analysis results are shown in Table 1.

From the table, the interaction effect of promotion way and products complementary is significant on purchase intention $(P=0.00<0.05)$, which deny the original hypothesis. Similarly, for perceived promotional benefit, the interaction between promotion way and Product complementarity is significant $(P=0.04<$ $0.05)$. But for the perceived promotional risk, the interaction between them is not significant $(P=0.11>0.05)$. Mainly, the promotion way has an impact on consumers' perceived promotional risk $(P=0.00<0.05)$. Therefore, there is a certain interaction effect between promotion way and product complementarity in consumer online shopping behavior, which can influence the network consumers' purchasing intention. The results provide support for hypothesis 1 .

On this basis, the product complementarity is further divided into two groups. Under the combination of different product complementarity and different price promotion, the average purchase intention of consumers is shown in Figure 1.

It can be seen that, in the case of complementarity of products, the estimated average value of the purchase intention resulting from the "price deduction over a given purchase amount" is greater than the "Unveil promotion price"; In the absence of complementarity of products, the estimated average value of purchase intention resulting from "price deduction over a given purchase amount" is less than "Unveil promotion price". Therefore, it can be explained "price deduction

Table 1. Promotion way and complementary interaction analysis.

\begin{tabular}{|c|c|c|c|c|c|c|}
\hline $\begin{array}{l}\text { Dependent } \\
\text { Variable }\end{array}$ & $\begin{array}{l}\text { Independent } \\
\text { Variable }\end{array}$ & $\begin{array}{c}\text { Type III } \\
\text { sum of squares }\end{array}$ & $\mathrm{df}$ & $\begin{array}{l}\text { Mean } \\
\text { Square }\end{array}$ & $\mathbf{F}$ & Sig \\
\hline \multirow{3}{*}{$\begin{array}{l}\text { Purchase } \\
\text { intention }\end{array}$} & Promotion way & 0.30 & 1 & 0.30 & 0.34 & 0.56 \\
\hline & Product complementarity & 8.87 & 1 & 8.87 & 10.21 & 0.00 \\
\hline & $\begin{array}{l}\text { promotion way } \times \\
\text { Product complementarity }\end{array}$ & 14.26 & 1 & 14.26 & 16.41 & 0.00 \\
\hline \multirow{3}{*}{$\begin{array}{c}\text { Perceived } \\
\text { promotional } \\
\text { benefit }\end{array}$} & Promotion way & 0.85 & 1 & 0.85 & 0.92 & 0.34 \\
\hline & Product complementarity & 11.32 & 1 & 11.32 & 12.35 & 0.00 \\
\hline & $\begin{array}{c}\text { promotion way } \times \\
\text { Product complementarity }\end{array}$ & 3.82 & 1 & 3.82 & 4.17 & 0.04 \\
\hline \multirow{3}{*}{$\begin{array}{l}\text { Perceived } \\
\text { promotional } \\
\text { risk }\end{array}$} & Promotion way & 9.04 & 1 & 9.04 & 9.59 & 0.00 \\
\hline & Product complementarity & 0.41 & 1 & 0.41 & 0.44 & 0.51 \\
\hline & $\begin{array}{c}\text { promotion way } \times \\
\text { Product complementarity }\end{array}$ & 2.50 & 1 & 2.50 & 2.65 & 0.11 \\
\hline
\end{tabular}




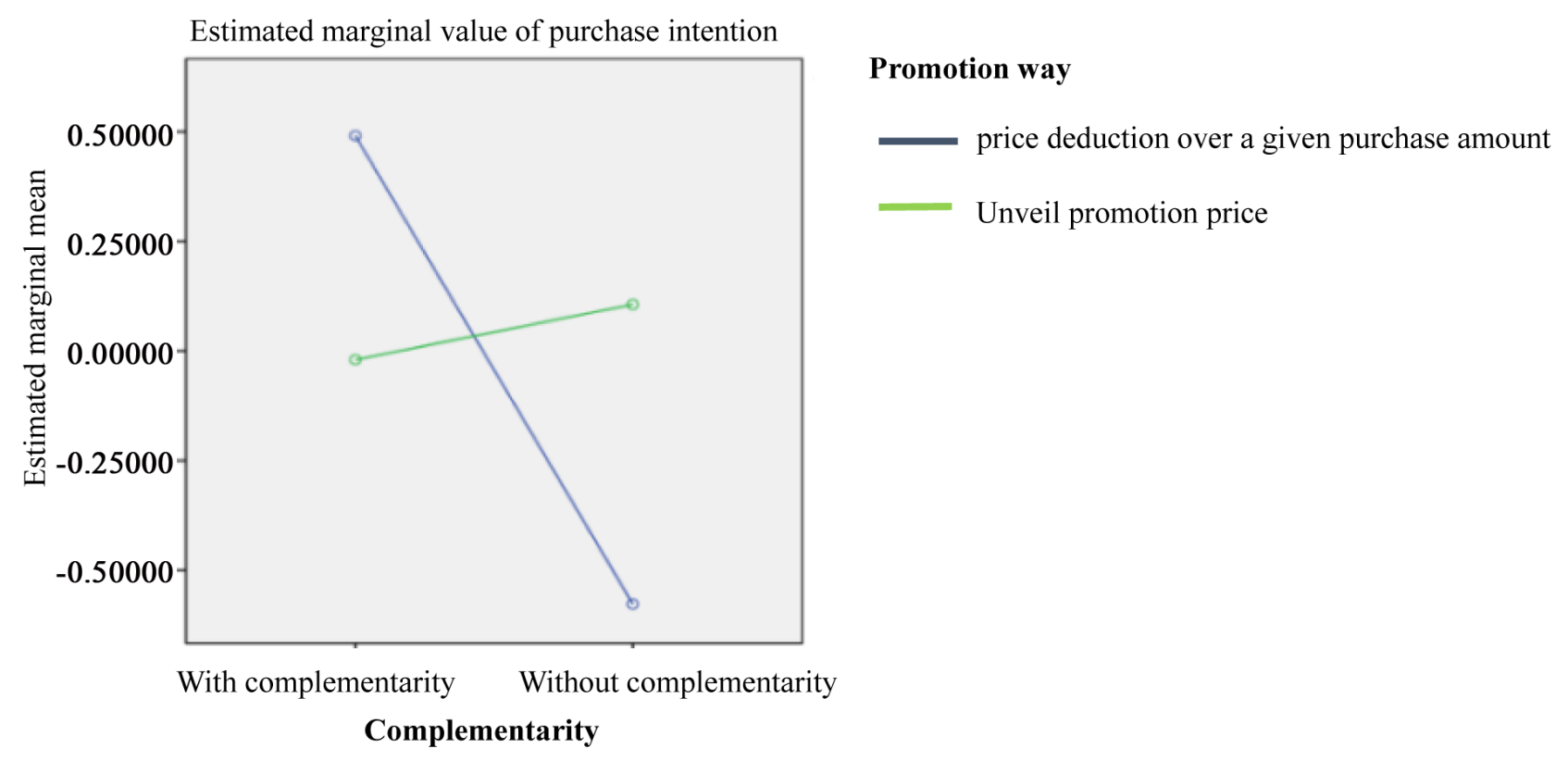

Figure 1. Average purchase intention analysis.

over a given purchase amount" can lead consumers to have a greater purchase intention in the case of complementarity of product; But "Unveil promotion price" can lead consumers to have a greater purchase intention in the absence of complementarity of product. The results provide support for hypothesis 1a and hypothesis $1 \mathrm{~b}$.

Finally, the paper comprehensively analyzes the influence of perceived promotional benefit and perceived promotional risk under different promotion way. Respectively, the estimated average values of perceived promotional benefit and perceived promotional risk are shown in Figure 2 and Figure 3.

From Figure 2 and Figure 3, in the two cases of product complementarity, "Unveil promotion price" bring greater perceived promotional risk and "price deduction over a given purchase amount" bring less perceived promotional risk. For perceived promotional benefit, "price deduction over a given purchase amount" bring higher perceived promotional benefit than "Unveil promotion price" in the case of complementarity of products; "Unveil promotion price" bring higher perceived promotional benefit than "price deduction over a given purchase amount" in the absence of complementarity of products. Moreover, No matter what kind of promotion way, it can bring more promotional benefit in the case of complementarity of products.

3) Mediating effect analysis

In order to test the mediating effects of perceived promotional benefit and perceived promotional risk, this study makes the following relevant analysis.

First of all, this study takes the perceived promotional benefit and perceived promotional risk as the independent variable, and takes the purchase intention as the dependent variable. The results of regression analysis are shown in Table 2. 
Perceived promotional risk of purchase intention

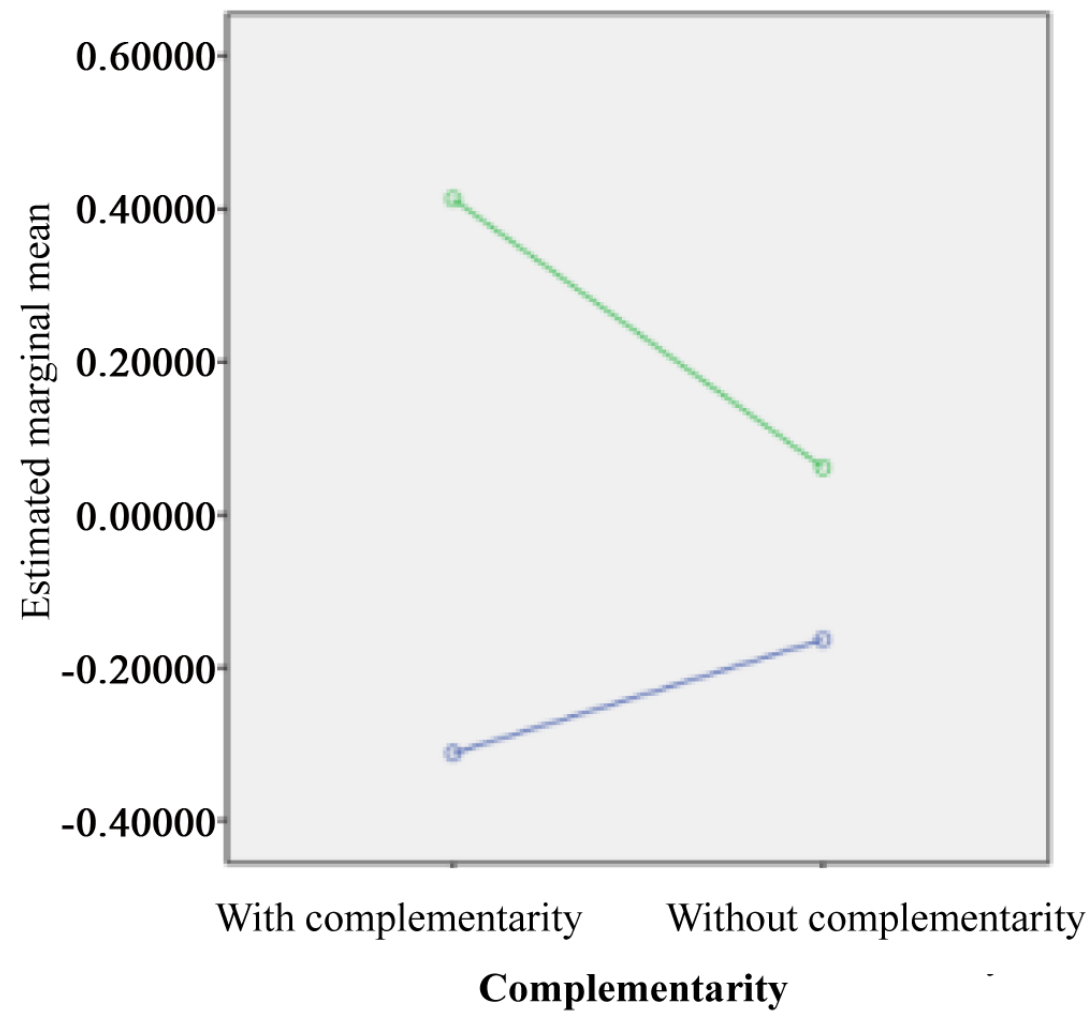

Figure 2. Average purchase intention analysis.

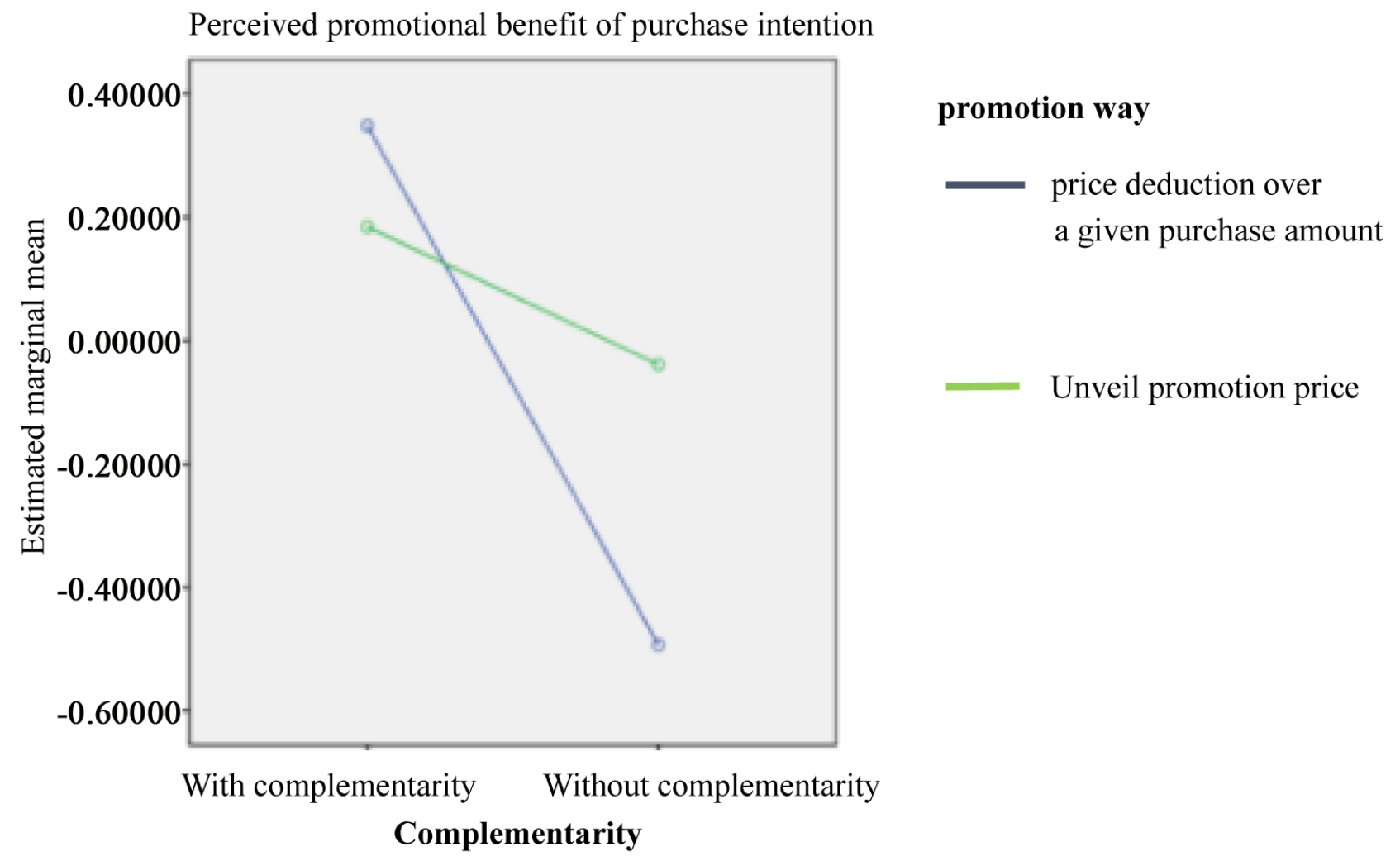

promotion way

price deduction over a given purchase amount Unveil promotion price

Figure 3. Average purchase intention analysis. 
Table 2. The results of linear regression analysis of perceived promotional benefit and perceived promotional risk on purchase intention.

\begin{tabular}{ccccccc}
\hline \multirow{2}{*}{ Model } & \multicolumn{2}{c}{$\begin{array}{c}\text { Non-standardized } \\
\text { coefficient }\end{array}$} & $\begin{array}{c}\text { Standardized } \\
\text { Coefficients }\end{array}$ & T & Sig \\
\cline { 2 - 4 } & B & Standard error & Beta & & \\
\hline Constant & 1.07 & 0.05 & & 0.00 & 1.00 \\
Perceived promotional benefit & 0.78 & 0.05 & 0.78 & 14.75 & 0.00 \\
Perceived promotional risk & -0.18 & 0.05 & -0.18 & -3.51 & 0.00 \\
\hline
\end{tabular}

$\mathrm{F}=109.00, \mathrm{P}=0.00, \mathrm{R}=762, \mathrm{R}^{2}=581$.

As shown in Table 2, the variance analysis of the regression model of purchase intention is $\mathrm{F}=109.00, P=0.00<0.05$, which shows that the regression model of purchase intention is statistically significant. In addition, $\mathrm{R}^{2}=0.58$ indicates that the regression model can explained $58.1 \%$ of the total variance of the dependent variable (purchase intention). Among them, perceived promotional benefit is positively correlated with the purchase intention, and the greater perceived promotional benefit, the greater purchase intention; Perceived promotional risk and purchase intention are negatively correlated, and the greater perceived promotional risk, the smaller purchase intention.

In addition, in the same situation of product complementarity, this study use AMOS software to analyze the mediating effect of perceived promotional benefit and perceived promotional risk in the purchase intention, the result is shown in Figure 4. The results show that the structural equation model $P=0.17>0.05$, so that the reasonable original hypothesis of the model can be accepted. Moreover, the overall model fits well the data: Comparative fit index [CFI] $=0.98$, Normed fit index $[\mathrm{NFI}]=0.92$, Incremental fit index $[\mathrm{IFI}]=0.98$, and Tucker-Lewis in$\operatorname{dex}[$ TLI $]=0.97$, which shows that the model fitting degree is better.

The coefficient estimation results shows that the impact of promotion way on purchase intention is minimum (unstandarized estimate $=0.15$ ) and is not significant $(P=0.38>0.05)$. The influence of Perceived promotional benefit (unstandarized estimate $=0.62, P<0.01$ ) and perceived promotional risk (unstandarized estimate $=0.18, P<0.05$ ) on purchase intention is significant and is obviously improved, and the indirect effects are greater than the direct effect of two paths.

Finally, using the Bootstrap test, we find that the direct effect of promotion way on purchase intention is not significant $(P=0.38>0.05)$. However, in the 95\% confidence interval, perceived promotional benefit significantly affect the purchase intention $(0.62, \mathrm{LLCI}=0.32, \mathrm{ULCI}=0.93)$, perceived promotional risk significantly influence the purchase intention $(-0.14$, LLCI $=-0.33$, ULCI $=$ -0.03). Therefore, perceived promotional benefit and perceived promotional risk play a mediating effect in the impact of promotion way on purchase intention, which validates the hypothesis of the study 2 . 


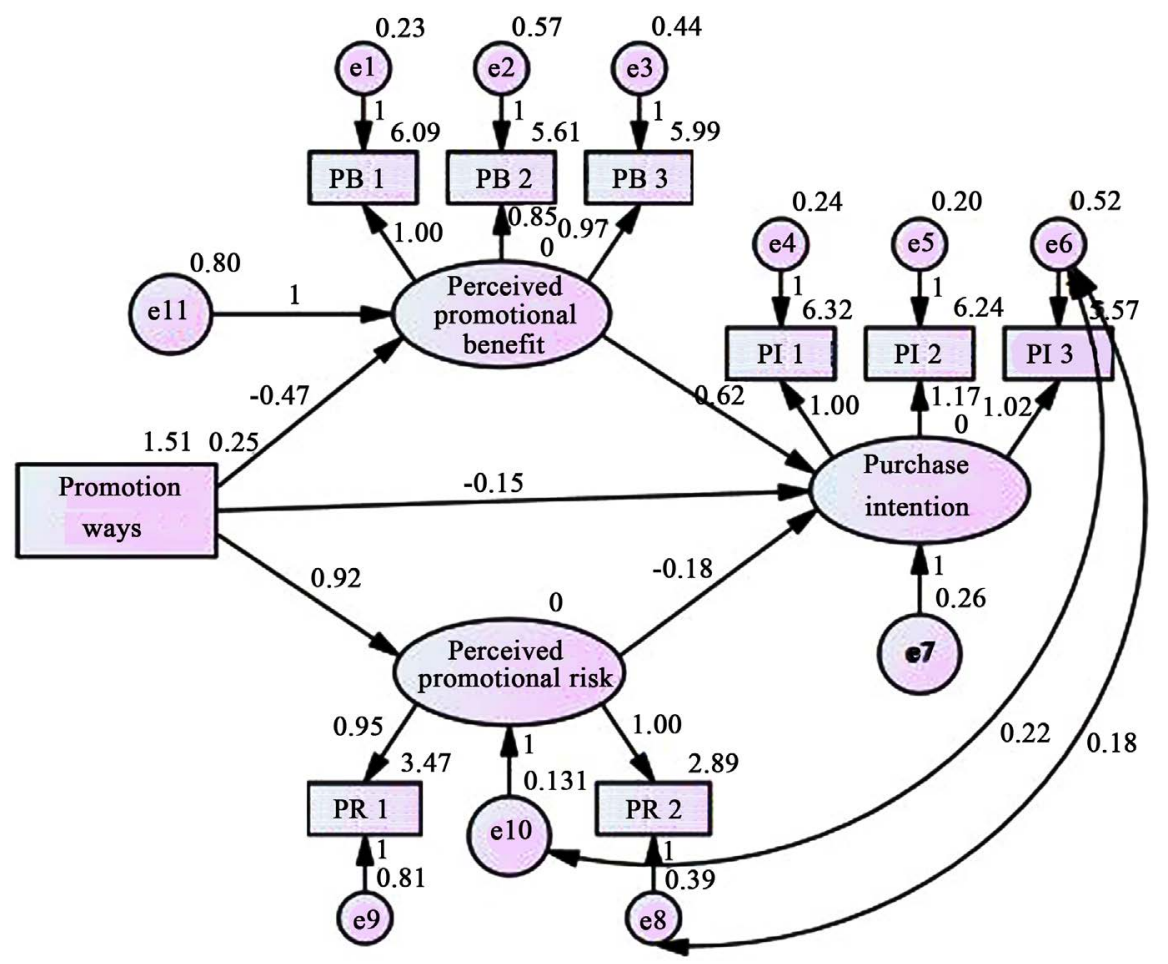

Figure 4. Mediator effect test analysis.

Using the method of Rong (2009) [29], the influence of one variable on another variable through a mediation variable is the indirect effect, and the calculation method is the product of path coefficient. In the case of complementarity of products, the indirect effect of the promotion way to purchase intention through perceived promotional benefit is 0.28 ; the indirect effect of the promotion way to purchase intention through perceived promotional risk is 0.42 . It can be seen that perceived promotional risk has more influence on consumers' purchasing intention when complementary exists among products. The hypothesis $2 \mathrm{a}$ was verified. In the absence of complementarity of products, the indirect effect of the promotion way to purchase intention through perceived promotional benefit is 0.29 ; the indirect effect of the promotion way to purchase intention through perceived promotional risk is 0.17 . It can be seen that perceived promotional benefit has more influence on consumers' purchasing intention when there is no complementarity between products. The hypothesis $2 b$ is verified.

\section{Conclusions}

\subsection{Research Conclusions}

This study explores the influence of online price promotion on purchase intention, and verifies the interaction effect of promotion way and products complementary on consumer purchase intention and the mediating effect of perceived promotional benefit and perceived promotional risk. The following conclusions are drawn from this study:

1) There is an interaction between promotion way and product complementarity, 
which leads to different consumers' purchasing intention. In the case of complementarity of products, "price deduction over a given purchase amount" caused greater consumer purchase intention than "unveiling promotion price"; In the absence of complementarity of products, "unveiling promotion price" caused greater consumer purchase intention than "price deduction over a given purchase amount".

2) Perceived promotional benefit and perceived promotional risk play a mediating role in the impact of price promotion and product complementarity on purchase intention. When complementary exists among products, perceived promotional risk has more influence on consumers' purchasing intention. When there is no complementarity between products, perceived promotional benefit has more influence on consumers' purchasing intention.

3) In terms of perceived promotional risk, whether or not there is complementarity between products, "Unveil promotion price" bring greater perceived promotional risk and "price deduction over a given purchase amount" bring less perceived promotional risk. For perception promotion benefit, "price deduction over a given purchase amount" brings higher perceived promotional benefit than "unveiling promotion price" in the case of complementarity of products; "unveiling promotion price" brings higher perceived promotional benefit than "price deduction over a given purchase amount" in the absence of complementarity of products. Moreover, no matter what kind of promotion way, it can bring more promotion benefit in the case of complementarity of products.

\subsection{Theoretical and Practical Contributions}

The results of this study prove that consumers' online consumer psychology and consumer behavior are different in different price promotion way, which enriches the relevant online promotion theory. The theoretical contributions are as follows: 1) based on the situation of the online shopping, this paper compares the different forms of the same price promotion influence on consumers' purchase intention, which enrich the research of online promotion ways. 2) the study found that there is an interaction between different price promotion methods and product complementarity, which have a significant impact on consumers' purchasing intention. And perceived promotional benefit and perceived promotional risk play a mediating role in the impact of price promotion and product complementarity on purchase intention. This not only supplements and improves the theory of online promotion, but also complements the research of product complementarity.

This study can also provide inspiration for the management of network platform and network business, help operators to have a better understanding of the consumer mental state, and develop more effective promotion strategies by using promotion way and product complementarity. Specifically, the practical meaning is reflected in: 1) based on the results of this study, online stores may select price promotion way according to the complementarity between promotional products, rather than blindly choose and imitate. When there is complementarity 
between products, the choice of "price deduction over a given purchase amount" can lead to greater consumers' purchasing intention; When there is no complementarity between products, choose "Unveil promotion price" can arouse more consumers' purchasing intention. 2) in order to enhance the effect of promotion, we can improve the consumers' purchasing intention from two aspects: increasing perceived promotional benefit and reducing perceived promotional risk. The perceived promotional risk can be reduced by using "price deduction over a given purchase amount" or selecting of complementary products; No matter what kind of promotion way, "Unveil promotion price" can bring more perceived promotional benefit than "price deduction over a given purchase amount" in the case of complementarity of products.

\subsection{Research Limitations and Prospects}

Although this study explores the interaction effect between promotion way and product complementarity, there are still some limitations that can be used as the direction of future research.

First of all, this research subjects are college students and the sample size is limited, which can not cover the crowd of the entire online shopping. As a result, certain theories or features in the study may not fully reflect the reality. In future study, researchers should adopt more diverse sample resources to improve the universality of the research results.

Secondly, this study only considered "price deduction over a given purchase amount" and "Unveil promotion price" of the two common network price promotion. But in reality, there are many online price promotion, such as additional discount. In addition, the form of "price deduction over a given purchase amount" also has many kinds, such as full 199 minus 100, full 299 minus 150 . There is no research on which kind of "full-down" form can attract consumers most. Therefore, future research may consider the impact of different combinations of online promotions and different forms of the same promotions on consumers' purchasing intention.

Finally, this study only discusses the influence of the boundary condition of product complementarity on consumers' purchase intention. Therefore, further research need to explore the impact of more valuable segmentation variables.

\section{References}

[1] China Internet Network Information Center (2017) The 39th China Internet Development Statistics Report. Beijing: China Internet Network Information Center.

[2] Han, R. and Tian, Z.L. (2005) An Empirical Study of the Influence of Promotion Types on Consumer Perceived Value and Behavior Intention. Management Science, 18, 85-91.

[3] Deng, X.F. (2002) Discussion on the Best Model of Product Price Promotion and Price Reduction. Reform of Economic System, 2002, 158-161.

[4] Raghubir, P., Inman, J.J. and Grande, H. (2004) The Three Faces Consumer of Promotions. California Management Review, 46, 23-42. 
https://doi.org/10.2307/41166273

[5] Sarin, S., Sego, T. and Chanvarasuth, N. (2003) Strategic Use of Building for Reducing Consumers' Perceived Risk Associated with Purchase of New High-Tech Products. Journal of Marketing Theory and Practice, 11, 71-83. https://doi.org/10.1080/10696679.2003.11658502

[6] Holbrook, M.B. (1994) Ethics in Consumer Research: An Overview and Prospects. Advance in Consumer Research for Consumer Research, 21, 566-571.

[7] Laurent, G., Chandon, P. and Wansink, B. (2011) Hedonic and Utilitarian Consumer Benefits of Sales Promotions. Hedonic and Utilitarian Consumer Benefits of Sales Promotions. Marketing Science Institute, Cambridge, MA.

[8] Kopalle, P.K., Rao, A.G. and Assunção, J.L. (1996) Asymmetric Reference Price Effects and Dynamic Price Policies. Marketing Science, 15, 60-85. https://doi.org/10.1287/mksc.15.1.60

[9] Bauer, R.A. (1960) Consumer Behavior as Risk Taking. In: Cox, D., Ed., Risk Taking and Information Handling in Consumer Behavior, Harvard University Press, Cambridge, MA, 389-398.

[10] Hu, S.S. (2011) Study on the Impact of Online Store's Promotion Strategy to the Purchase Intention of Consumers. Jiangxi Agricultural University, Nanchang.

[11] Seymour, B. (1950) The Relationship between Preference and Purchase of Brands. Journal of Marketing, 15, 145-157.

[12] Bagozzi, R.P., Baumgartner, J. and Yi, Y. (1989) An Investigation into the Role of Intentions as Mediators of the Attitude-Behavior Relationship. Journal of Economic Psychology, 10, 35-62.

[13] Shin, H.S., Hanssens, D.M., Kim, K.I. and Gajula, B. (2011) Impact of Positive vs. Negative e-Sentiment on Daily Market Value of High-Tech Products.

[14] Parasuraman, A. (1997) Reflection on Gaining Competitive Advantage through Customer Value. Journal of the Academy of Marketing Science, 25, 154-161. https://doi.org/10.1007/BF02894351

[15] Fishbein, M. and Ajzen, I. (1975) Belief, Attitude, Intention and Behavior: An Introduction to Theory and Research. Philosophy \& Rhetoric, 41, 842-844.

[16] Dodds, W.B., Moriroe, K.B. and Grewal, D. (1991) Effects of Price Brand and Store Information on Buyers Produce Evaluation. Journal of Marketing Research, 28, 307-319. https://doi.org/10.2307/3172866

[17] Zhu, Z. (1989) Psychology Dictionary. Beijing Normal University Press, Beijing, 861.

[18] Tversky, A. and Kahneman, D. (1981) The Framing of Decisions and the Psychology of Choice. Science, 211, 453-458. https://doi.org/10.1126/science.7455683

[19] Hu, Z. (2012) The Impact of Free Goods on the Spread of Complementary Products. China Management Science, No. 6, 167-175.

[20] Xu, Y., Tao, X. and Ji, X. (2015) Network Effect and Strategy Selection of New Energy Vehicle Market Introduction Period. Industrial and Technical Economy, No. 3, 3-11.

[21] Duan, W. (2007) Research on the Implementation of New Product Complementary Strategy in Network Market. Forecasting, 26, 15-20.

[22] Krishna, A., Briesch, R., Lehmann, D.R. and Yuan, H. (2002) A Meta-Analysis of the Impact of Price Presentation on Perceived Savings. Journal of Retailing, 78, 101-118. 
[23] Tao, X. (2011) Empirical Study on the Influence of Bundling Strategy on Customer Loyalty in Retail Industry. Journal of Beijing Technology and Business University (Social Science Edition), 26, 12-18.

[24] Sondergaard, H.A., Grunert, K.G. and Scholderer, J. (2005) Consumer Attitudes to Enzymes in Food Production. Trends in Food Science \& Technology, 16, 466-474.

[25] Shi, J. (2009) The Influence of Perceived Risk and Perceived Value on Online Shopping. Peking University.

[26] Chandon, P., Wansink, B. and Laurent, G. (2000) A Benefit Congruency Framework of Sales Promotion Effectiveness. Journal of Marketing, 64, 65-81. https://doi.org/10.1509/jmkg.64.4.65.18071

[27] Sweeney, J.C., Soutar, G.N. and Johnson, L.W. (1999) The Role of Perceived Risk in the Quality-Value Relationship: A Study in a Retail Environment. Journal of Retailing, 75, 77-105.

[28] Wen, Z., Hou, J.T. and Zhang, L. (2005) The Comparison and Application of Moderating Effects and Mediating Effects. Acta Psychologica Sinica, 37, 268-274.

[29] Rong, T. (2009) AMOS and Research Methods. Chongqing University Press, Chongqing, 169. 